\title{
On Polyethylene Chain Generation Through Chemical Crosslinking of Isotactic Polypropylene
}

\author{
Saïd Bouhelal, ${ }^{1}$ M. Esperanza Cagiao, ${ }^{2}$ Antonio Bartolotta, ${ }^{3}$ Gaetano Di Marco, ${ }^{3}$ \\ Leoncio Garrido, ${ }^{4}$ Djafer Benachour, ${ }^{1}$ Francisco J. Baltá Calleja ${ }^{2}$ \\ ${ }^{1} L M P M P$, Faculty of Engineering, Ferhat Abbas University, Sétif, Algeria \\ ${ }^{2}$ Instituto de Estructura de la Materia, CSIC, 28006 Madrid, Spain \\ ${ }^{3}$ Istituto per $i$ Processi Chimico-Fisici, Sezione di Messina, CNR, Via La Farina 237, I-98123 Messina, Italy \\ ${ }^{4}$ Instituto de Ciencia y Tecnología de Polímeros, CSIC, 28006 Madrid, Spain
}

Received 16 March 2009; accepted 9 June 2009

DOI 10.1002/app.30903

Published online 1 December 2009 in Wiley InterScience (www.interscience.wiley.com).

\begin{abstract}
Crosslinked isotactic polypropylene (iPP) was prepared by reactive blending using dicumyl peroxide and active sulfur. The modified material was characterized by means of several techniques: dynamic mechanical thermal analysis, differential scanning calorimetry, Fourier transform infrared spectroscopy, and nuclear magnetic resonance $\left({ }^{13} \mathrm{C}\right.$ solid state NMR). Analysis of results using the above techniques confirms that, during the crosslinking process, new ethylenic chains are generated at expenses of the initially present iPP. Furthermore, a balance between the amount of missing iPP and the proportion of newly created polyethylene (PE) is observed.
\end{abstract}

The newly formed PE is semicrystalline, having a degree of crystallinity of about $30 \%$. The amorphous component of the generated PE is thought to contribute to the high impact strength of the crosslinked samples when compared to the unmodified iPP. In light of the results obtained by the different techniques, an attempt to describe the emerging structure of the new crosslinked iPP material is proposed. (C) 2009 Wiley Periodicals, Inc. J Appl Polym Sci 116: 394-403, 2010

Key words: reactive extrusion; crosslinking; differential scanning calorimetry; FTIR; NMR

\section{INTRODUCTION}

A new method for the preparation of reversibly crosslinking isotactic polypropylene (iPP) was recently developed in our laboratory. ${ }^{1}$ The crosslinked iPP (in what follows, indicated by X-iPP) offers considerable advantages, such as a ductile fracture, in contrast to the brittle fracture exhibited by the unmodified iPP. In addition, the impact strength of the modified material increases by a factor of $4-7$ with reference to the initial value. ${ }^{2}$ The molecular network formed also confers a better processability to the modified material. These outstanding properties make of X-iPP an optimum candidate for many attractive applications. Furthermore, as previously shown, ${ }^{2,3}$ the crosslinking reaction of iPP generates new ethylenic chains. Thus, the present work has been undertaken mainly to confirm this particular aspect, i.e., the generation of ethylenic chains during the crosslinking process. In addition,

Correspondence to: F. J. Baltá Calleja (embalta@iem.cfmac. csic.es).

Contract grant sponsor: Ministerio de Ciencia e Innovación; contract grant number: No FIS2007-60534.

Journal of Applied Polymer Science, Vol. 116, 394-403 (2010) (c) 2009 Wiley Periodicals, Inc. it is noteworthy the fact that it is possible to perform the complete procedure in only one fast step. The method currently used to perform the crosslinking process is the reactive extrusion, which modifies the polypropylene architectural structure. The scheme of this reaction is as follows:

$$
\mathrm{iPP}+\mathrm{X}_{\text {agent }} \rightarrow \mathrm{iPP}+\mathrm{X} \text {-iPP }+\mathrm{PE}
$$

The term $X_{\text {agent }}$ is used to denote the "crosslinking agent".

In general, the procedures developed for the crosslinking of polyolefins (PO) are mainly focused on polyethylene (PE). Crosslinked PE is widely used in industrial scale, for instance, in the manufacture of wire and cable coatings, and in the preparation of heat shrinkable films. ${ }^{4,5}$ PE can be easily crosslinked by means of an organic peroxide that can create radicals by a reaction of decomposition, or by irradiation with an electron or $\gamma$-rays beam. ${ }^{6,7}$ On the contrary, iPP has been considered as a noncrosslinkable polymer until the work of Busfield. ${ }^{8}$ This is due to the fact that, if iPP is either irradiated or subjected to the action of an oxy radical of peroxide, the $\beta$ scission degradation process predominates over the crosslinking mechanism. ${ }^{8}$ The reason is the low stability of the tertiary hydrogen atoms of macroradicals. ${ }^{9}$ In fact, controlled $\beta$-scission degradation 
processes have been developed to adjust the molecular weight distribution of the PP obtained by conventional Ziegler-Natta catalyst systems, to improve the processability of the material, and develop grades with specific rheological behavior. ${ }^{10,11}$ The fragmentation of iPP during the crosslinking reaction can be prevented by addition of a crosslinking coagent. The latter is a molecule capable to react with the iPP macroradicals by means of an addition reaction before fragmentation occurs. Macroradicals are, then, changed to more stable forms, which do not experience the scission. Efficient coagents are those having two or more active groups in the molecule, so that they can react with two or more macroradicals. The crosslinks are then constituted by the coagent molecules bound to the network. Examples of crosslinking coagents are, among others, polyfunctional monomers, i.e., bi-, tri-, and tetraacrylates; also, vinyl compounds, sulfur, and sulfur-containing chemicals, as thiourea, etc. Hydroquinone and benzoquinone are considered as extremely efficient coagents. ${ }^{12,13}$ In recent years, new methods to achieve the crosslinking of iPP have been consequently developed. ${ }^{14-16}$

The materials intervening in the present method are: iPP, an organic peroxide, sulfur (S), an accelerator (or a mixture of them), and potassium persulfate. The so-called "crosslinking agent" is constituted by the peroxide, the sulfur, and the accelerator. The samples were prepared by extrusion, though any other processing methods used in the industry for thermoplastic materials are also suitable, i.e., blow, injection or compression molding. For this reason, the modified polymers can be used to produce many different articles.

The crosslinking process is a homolytic chemical reaction. The principle of the crosslinking mechanism is to create macroradicals and make them act immediately on sulfur before the reaction of termination occurs. The first step is the peroxide decomposition, which originates the reaction of initiation; this, in turn, gives rise to the formation of macroradicals with a very short lifetime. The chains are linked by sulfur atoms (coupling reaction), through the formation of a tri-dimensional, heat-resistant, network. The interchain bridges can be: a sulfur atom, a polysulfide $-(\mathrm{S})_{x^{-}}$, or a cyclic S-compound. The accelerators increase the sulfur activation rate. Thus, the macro-radicals' formation and their coupling reaction with the sulfur originate at the same time, and an optimum crosslinking degree for each formulation is obtained. The addition of potassium persulfate increases the macro-radicals' lifetime. More details are given in. ${ }^{1}$

The composition of the blend has to be calculated by taking into account the desired degree of crosslinking. This, in turn, depends on the radical perox- ide efficiency, and on the activation rate. For this reason, in every experiment it is necessary to consider the transformation temperature, and the particular characteristics of the extrusion or the processing equipment to be used.

The aims of this study are two-fold:

a. To confirm, by using different techniques, the generation of ethylenic chains as a consequence of the iPP crosslinking process.

b. To examine the structure of the new PE chains.

\section{EXPERIMENTAL}

\section{Materials}

The materials used in this investigation were:

iPP: Sabic-Vestolen 9000-67404; supplied by Chemische Werke Hülls, Germany.

Dicumyl peroxide: DCP 96\% activity; supplied by NORAX.

Sulfur, S; supplied by Wuxi Huasbeng Chemical additives Factory, China.

Potassium persulfate; supplied by Innochem, Belgium.

The three accelerators used were: tetramethyl tiuram monosulphide (TMTM), tetramethyl tiuram disulphide (TMTD) and 2, 2', dibenzothiazol disulphide (MBTS). They were supplied by RhônePoulenc, France.

As it was indicated earlier, the peroxide, the sulfur, and the above accelerators constitute the "crosslinking agent".

\section{Blend preparation}

For the preparation of the blends, the sulfur and the peroxide are used in equal concentration. In all samples, the amount of sulfur and peroxide was 0.2 or $0.4 \mathrm{wt} \%$. The accelerator was always $1 / 4$ of the sulfur and peroxide concentration. The six formulations used are shown in Table I.

As a first step, the iPP, the crosslinking agent and the potassium persulfate were mixed in the solid state, using a few drops of vegetal oil to wet and improve the degree of dispersion of the different components within the granules of the iPP. Then, the obtained mixture was introduced into a single screw laboratory extruder (Prolabo 1989) having the following characteristics: $\mathrm{L} / \mathrm{D}=20$; screw diameter $=25 \mathrm{~mm}$; screw speed $=60$ turns $/ \mathrm{min}$. The selected residence time was about $3 \mathrm{~min}$. The temperature profile used in the three stages was: feed zone $=$ $155^{\circ} \mathrm{C}$; compression zone $=180^{\circ} \mathrm{C}$; homogenization 
TABLE I

Sample Compositions

\begin{tabular}{cccc}
\hline Sample & $\begin{array}{c}\text { Peroxide } \\
\text { content }(\%)\end{array}$ & $\begin{array}{c}\text { Sulfur } \\
\text { content }(\%)\end{array}$ & $\begin{array}{c}\text { Accelerator } \\
\text { content }(\%)\end{array}$ \\
\hline iPP & - & - & - \\
1 & 0.2 & 0.2 & 0.05 (TMTD) \\
2 & 0.4 & 0.4 & 0.1 (TMTD) \\
3 & 0.2 & 0.2 & 0.05 (TMTM) \\
4 & 0.4 & 0.4 & 0.1 (TMTM) \\
5 & 0.2 & 0.2 & 0.05 (MBTS) \\
6 & 0.4 & 0.4 & 0.1 (MBTS) \\
\hline
\end{tabular}

zone $=200^{\circ} \mathrm{C}$. To achieve a homogeneous blend, every extrusion cycle was repeated twice. ${ }^{1,2}$

\section{Techniques}

Dynamic mechanical thermal analysis (DMTA)

Dynamic mechanical thermal properties (mechanical loss factors $\tan \delta$, and storage Young modulus $E^{\prime}$ ) were investigated in the $-150 \leq \mathrm{T} \leq 170^{\circ} \mathrm{C}$ temperature and $0.3-30 \mathrm{~Hz}$ frequency ranges by using a dynamic mechanical thermal analyzer (DMTA) from Polymer Laboratories model MK II. The samples were tested in a double cantilever driven in bending mode with a fixed displacement $( \pm 16 \mu \mathrm{m})$. A heating rate of $2^{\circ} \mathrm{C} / \mathrm{min}$ was employed over the whole temperature range.

\section{Differential scanning calorimetry (DSC)}

Thermograms of all the samples were obtained by using a Perkin-Elmer Pyris1 differential scanning calorimeter (DSC), calibrated with indium and zinc standards. The calorimetric runs were performed using 5-10 $\mathrm{mg}$ of sample with a heating rate of $20^{\circ} \mathrm{C} / \mathrm{min}$ in the -30 to $200^{\circ} \mathrm{C}$ temperature interval under a constant flux of nitrogen at $0.1 \mathrm{~L} / \mathrm{min}$. All DSC curves are baseline subtracted and normalised to $1 \mathrm{mg}$ of sample. The first run was analyzed in all cases.

Fourier transform infrared spectroscopy (FTIR) measurements

Fourier transform infrared spectroscopy (FTIR) spectra of the film samples were recorded using a Perkin Elmer model Spectrum GX Series equipped with deuterated triglycine sulphate detector (DTGS); data were collected with a resolution of $2 \mathrm{~cm}^{-1}$ within 256 scans. The range $3000-2700 \mathrm{~cm}^{-1}$ of the spectra was registered by using a HATR (Horizontal Attenuated Total Reflectance) accessory having a top plate fitted with a ZnSe crystal, while the remaining part of the spectra was performed in transmission mode with a $1 \mathrm{~cm}^{-1}$ window.
Nuclear magnetic resonance $\left({ }^{13} \mathrm{C}\right.$ solid state NMR)

Representative samples were cut in small pieces (about $1 \mathrm{~mm}^{2}$ ), packed in $4 \mathrm{~mm}$ OD zirconia rotors and sealed with Kel-f ${ }^{\mathrm{TM}}$ caps.

${ }^{13} \mathrm{C}$ solid state NMR measurements were performed in a Bruker Avance ${ }^{\mathrm{TM}} 400$ spectrometer equipped with a $89 \mathrm{~mm}$ wide bore, $9.4 \mathrm{~T}$ superconducting magnet $\left({ }^{13} \mathrm{C}\right.$ Larmor frequency at 100.61 $\mathrm{MHz}$ ). All reported data were acquired with a standard Bruker double resonance $4 \mathrm{~mm}$ cross-polarization $(\mathrm{CP}) /$ magic angle spinning (MAS) NMR probe head using $90^{\circ}{ }^{1} \mathrm{H}$ and ${ }^{13} \mathrm{C}$ pulse lengths between 3.0 and $4.6 \mu \mathrm{s}$. The MAS spinning rates were 5.0 $\mathrm{kHz}$. The contact time for ${ }^{13} \mathrm{C} \mathrm{CP} / \mathrm{MAS}$ experiments was $1.0 \mathrm{~ms}$ and the repetition rate $3 \mathrm{~s}$. High power proton decoupling with a $B_{\text {eff }}$ of $75 \mathrm{kHz}$ was used. The number of scans averaged for each spectrum was 4000. All FIDs were processed using the spectrometer manufacturer's software. The spectra were externally referenced to adamantane as a secondary reference to TMS.

\section{RESULTS}

\section{DMTA}

Figure 1(a) shows the temperature dependence of the mechanical modulus $\mathrm{E}^{\prime}$ at a frequency of $0.3 \mathrm{~Hz}$ for all the crosslinked samples, as compared to that of neat iPP. At least three slopes are evident in the mechanical spectra of all the specimens. With increasing frequency, the intersection of the slopes shifts to higher temperatures (not shown here), as expected for thermally activated relaxation processes. The intersection points [Fig. 1(a)] correspond to the relaxations associated to local $(\gamma)$ and segmental $\left(\alpha\right.$ and $\left.\alpha^{\prime}\right)$ motions of the studied materials.

The $\gamma$-relaxation is related with local motions of the methyl group that occur within the amorphous phase of iPP. ${ }^{17,}$

The $\alpha$-relaxation, also known as $\beta$-relaxation has been identified with the glass transition of the amorphous phase, although the interactions with the crystal phase also have to be considered. ${ }^{17}$

Finally, the $\alpha^{\prime}$-relaxation is related to segmental motions within the crystalline phase. ${ }^{17}$ Jourdan et al. ${ }^{19}$ have reported that this latter relaxation is originated by the diffusion of defects in the crystal. However, the amorphous phase that surrounds the crystallites also contributes to this process. ${ }^{17}$ In fact, this broad relaxation, approximately from 40 to $100^{\circ} \mathrm{C}$, is a complex mode hiding several loss processes. $^{20}$

As the temperature is increased from $-150^{\circ} \mathrm{C}$, Log $\left(E^{\prime}\right)$ slowly decreases and passes through the $\gamma$-relaxation, located at about $-110^{\circ} \mathrm{C}($ at $0.3 \mathrm{~Hz})$. At $0^{\circ} \mathrm{C}$ approximately, $E^{\prime}$ exhibits for all the samples a 


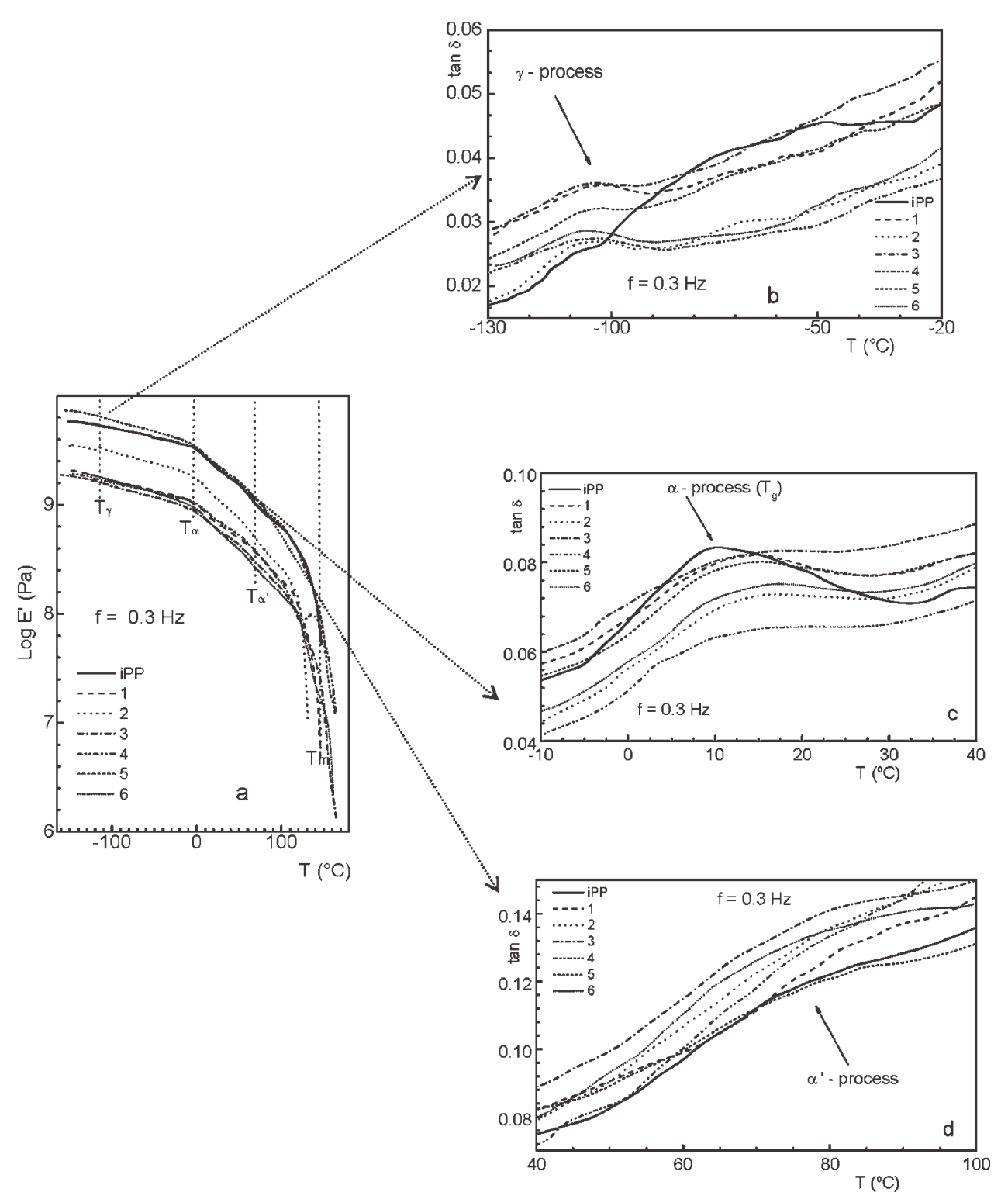

Figure 1 (a) Temperature T dependence of the mechanical modulus $E^{\prime}$ at a frequency $f=0.3 \mathrm{~Hz}$ for the investigated samples. 1(b)-(d) Variation of $\tan \delta$ as a function of temperature $\mathrm{T}$ at $f=0.3 \mathrm{~Hz}$ in the intervals: $(\mathrm{b})-130 \leq \mathrm{T} \leq-20^{\circ} \mathrm{C}$, (c) $-10 \leq \mathrm{T} \leq 40^{\circ} \mathrm{C}$, and (d) $40 \leq \mathrm{T} \leq 100^{\circ} \mathrm{C}$. See Table I for sample compositions.

second relaxation which is associated to the glass to rubber transition ( $\alpha$-relaxation or dynamic $T_{g}$ ), exhibiting the familiar shifts to higher temperatures, the higher the driving frequency (not shown here). Finally, for higher values of temperature, the $\alpha^{\prime}$-relaxation process appears, followed by the melting. It is noteworthy that, in sample 4 , a hardening process sets in just above $120^{\circ} \mathrm{C}$ [see Fig. 1(a)]. The latter is a temperature where PE usually melts.

The values for the mechanical modulus $E^{\prime}$ at room temperature derived from Figure 1(a) are listed in Table II, together with other mechanical properties. It is seen that all samples have modulus values lower than that of pure iPP, except sample 5 which presents a value almost identical to that of iPP.
Figures $1(b-d)$ show the variation of $\tan \delta$ as a function of temperature $\mathrm{T}$, obtained at a frequency $f=0.3 \mathrm{~Hz}$. In this plot, three well defined regions appear that correspond to the three relaxations already shown in Figure 1(a). These regions are localized in the following intervals: (a) $-130 \leq \mathrm{T} \leq$ $30^{\circ} \mathrm{C}$ ( $\gamma$-process), $(\mathrm{b})-10 \leq \mathrm{T} \leq 30^{\circ} \mathrm{C}$ ( $\alpha$-process or dynamic $T_{g}$ ), (c) $50 \leq \mathrm{T} \leq 100^{\circ} \mathrm{C}$ ( $\alpha^{\prime}$-process).

In case of the original iPP sample, the low-T process [Fig. 1(b)] is rather spread out towards temperatures higher than $-110^{\circ} \mathrm{C}$. In the crosslinked material, the temperature range of the $\gamma$-process reduces to a rather narrower dispersion region around $-110^{\circ} \mathrm{C}$.

With regards to the cooperative $\alpha$-relaxation process, or dynamic $T_{g}$ [located in the interval between 
TABLE II

Impact Strength, Experimental $H_{\exp }$ and Calculated $H_{\text {calc }}$ Microhardness and Mechanical Modulus at Room Temperature $E^{\prime 25^{\circ}}$ for Unmodified and Crosslinked iPP

\begin{tabular}{ccccc}
\hline Sample & $\begin{array}{c}\text { Impact } \\
\text { strength } \\
\left(\mathrm{kJ} / \mathrm{m}^{2}\right)^{\mathrm{a}}\end{array}$ & $\begin{array}{c}H_{\text {exp. }} \\
(\mathrm{MPa})^{\mathrm{a}}\end{array}$ & $\begin{array}{c}H_{\text {calc. }} \\
(\mathrm{MPa})\end{array}$ & $\begin{array}{c}\left(E^{\prime}\right)^{25^{\circ}} \\
(\mathrm{GPa})\end{array}$ \\
\hline iPP & 4.47 & $89 \pm 8$ & - & 2.10 \\
1 & 19.40 & $78 \pm 6$ & 76 & 0.67 \\
2 & 15.91 & $72 \pm 4$ & 73 & 1.10 \\
3 & 24.47 & $79 \pm 6$ & 73 & 0.58 \\
4 & 18.25 & $70 \pm 4$ & 71 & 0.70 \\
5 & 30.94 & $88 \pm 7$ & 77 & 2.24 \\
6 & 19.79 & $81 \pm 5$ & 72 & 0.56 \\
\hline
\end{tabular}

${ }^{\text {a }}$ Values taken from Ref. 2.

$-10^{\circ} \mathrm{C}$ and $30^{\circ} \mathrm{C}$, Figure $\left.1(\mathrm{c})\right]$, we observe that, in some of the modified samples, the dispersion peak moves towards temperatures $3-5^{\circ} \mathrm{C}$ higher than the value found for the original iPP, i.e., $9^{\circ} \mathrm{C}$. This effect is also related with the crosslinking process.

The $\alpha^{\prime}$-relaxation process is shown in Figure 1(d). In sample number 1 the maximum is shifted to higher temperature $\left(\sim 79^{\circ} \mathrm{C}\right)$ than the pure iPP $\left(\sim 72^{\circ} \mathrm{C}\right)$. The relaxation intensity in the crosslinked samples is similar (samples 3 and 6) or smaller that in the unmodified iPP. In addition, the temperature range where the $\alpha^{\prime}$-relaxation occurs is slightly wider in samples 1, 3, and 5 .

Finally, in the high $\mathrm{T}$ region (not shown here), the melting of the samples takes place.

\section{DSC}

Figure 2 illustrates the DSC scans at $20^{\circ} \mathrm{C} / \mathrm{min}$ of all the samples. Whereas the iPP thermogram shows a melting endotherm of the polymer at about $167^{\circ} \mathrm{C}$, in the crosslinked samples a second melting peak, at lower temperature than that of iPP, appears. The appearance of this peak, already detected in a previous study, ${ }^{2}$ was related with the presence of PE chains, eventually formed by the action of the peroxide and potassium persulfate on some of the tertiary

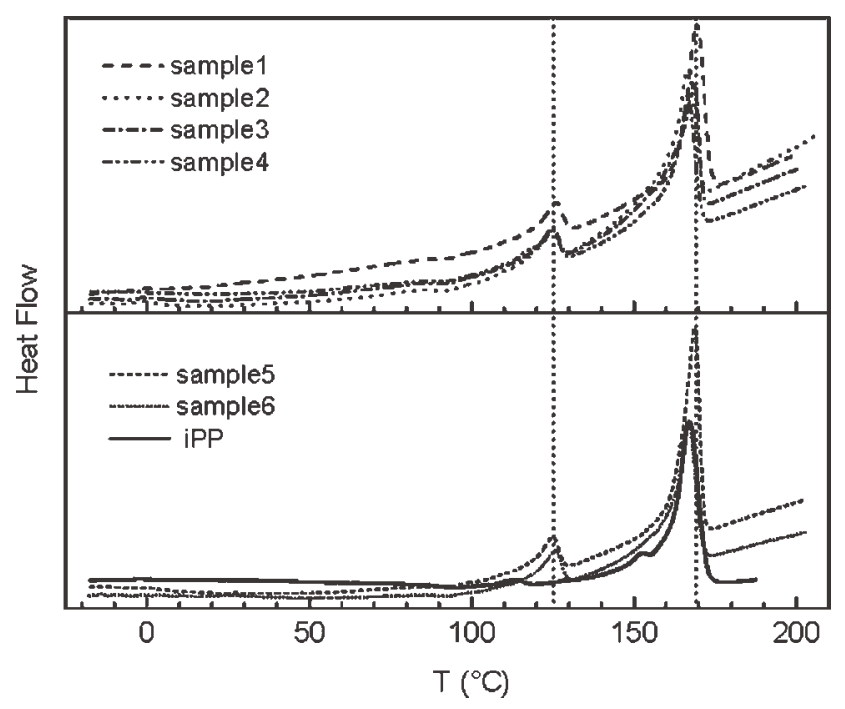

Figure 2 DSC thermograms of the unmodified and crosslinked iPP samples. See Table I for sample compositions.

carbon atoms of the iPP. Table III reports the values of the peak temperatures and the enthalpies associated to the melting processes observed.

The degree of crystallinity, $\alpha_{\mathrm{DSC}}$, for each component, i.e., for iPP and for the newly created PE was derived from the DSC study using the following formula: $\alpha_{\mathrm{DSC}}=\Delta H_{m} / \Delta H_{m}^{\infty}$, where $\Delta H_{m}$ and $\Delta H_{m}^{\infty}$ are the experimental melting enthalpy and the melting enthalpy for an infinitely thick crystal, respectively. We have taken the values $\Delta H_{m}^{\infty}=207.33 \mathrm{~J} / \mathrm{g}$ for $\mathrm{iPP}^{21}$ and $\Delta H_{m}^{\infty}=293.86 \mathrm{~J} / \mathrm{g}$ for PE. ${ }^{21}$ Table III lists the crystallinity values found for both components iPP and PE, in the crosslinked samples. The obtained results show that, both, $\alpha^{\mathrm{PE}}$ and $\alpha^{\mathrm{iPP}}$ show quite similar values in all the modified materials. In addition, the $\alpha^{\mathrm{iPP}}$ values for the modified samples are only slightly lower than that for the pure iPP, which is 0.40 .

The thermodynamic crystal size $l_{c}$ was derived for each maximum using the Thomson-Gibbs equation:

$$
T_{m}=T_{m}^{0}\left[1-\left(2 \sigma_{e} / \Delta H_{m}^{\infty} l_{c}\right)\right]
$$

\section{TABLE III}

Melting Enthalpies $\Delta H^{\mathrm{PE}}, \Delta H^{\mathrm{iPP}}, \Delta \boldsymbol{H}_{\mathrm{tot}}$ and Melting Points $T_{m}^{\mathrm{PE}}, T_{m}^{\mathrm{iPP}}$, from DSC; Crystallinity Values $\alpha^{\mathrm{PE}}$ and $\alpha^{\mathrm{iPP}}$ Derived from DSC

\begin{tabular}{cccccccc}
\hline Sample & $\Delta H^{\mathrm{PE}}(\mathrm{J} / \mathrm{g})$ & $T_{m}^{\mathrm{PE}}\left({ }^{\circ} \mathrm{C}\right)$ & $\alpha^{\mathrm{PE}}$ & $\Delta H^{\mathrm{iPP}}(\mathrm{J} / \mathrm{g})$ & $T_{m}^{\mathrm{iPP}}\left({ }^{\circ} \mathrm{C}\right)$ & $\Delta H_{\text {tot }}(\mathrm{J} / \mathrm{g})$ & $\alpha^{\mathrm{iPP}}$ \\
\hline iPP & - & - & - & 83.3 & 167.3 & 83.3 & 0.40 \\
1 & 13.1 & 125.9 & 0.28 & 70.6 & 169.5 & 83.7 & 0.41 \\
2 & 11.4 & 124.9 & 0.28 & 68.4 & 166.7 & 79.8 & 0.38 \\
3 & 11.9 & 125.0 & 0.27 & 68.4 & 168.9 & 80.3 & 0.39 \\
4 & 14.5 & 125.0 & 0.27 & 64.6 & 166.7 & 79.1 & 0.38 \\
5 & 12.5 & 125.0 & 0.30 & 75.3 & 168.9 & 87.8 & 0.42 \\
6 & 12.9 & 125.6 & 0.27 & 66.5 & 166.7 & 79.4 & 0.38 \\
\hline
\end{tabular}

Samples are as in Table I. 

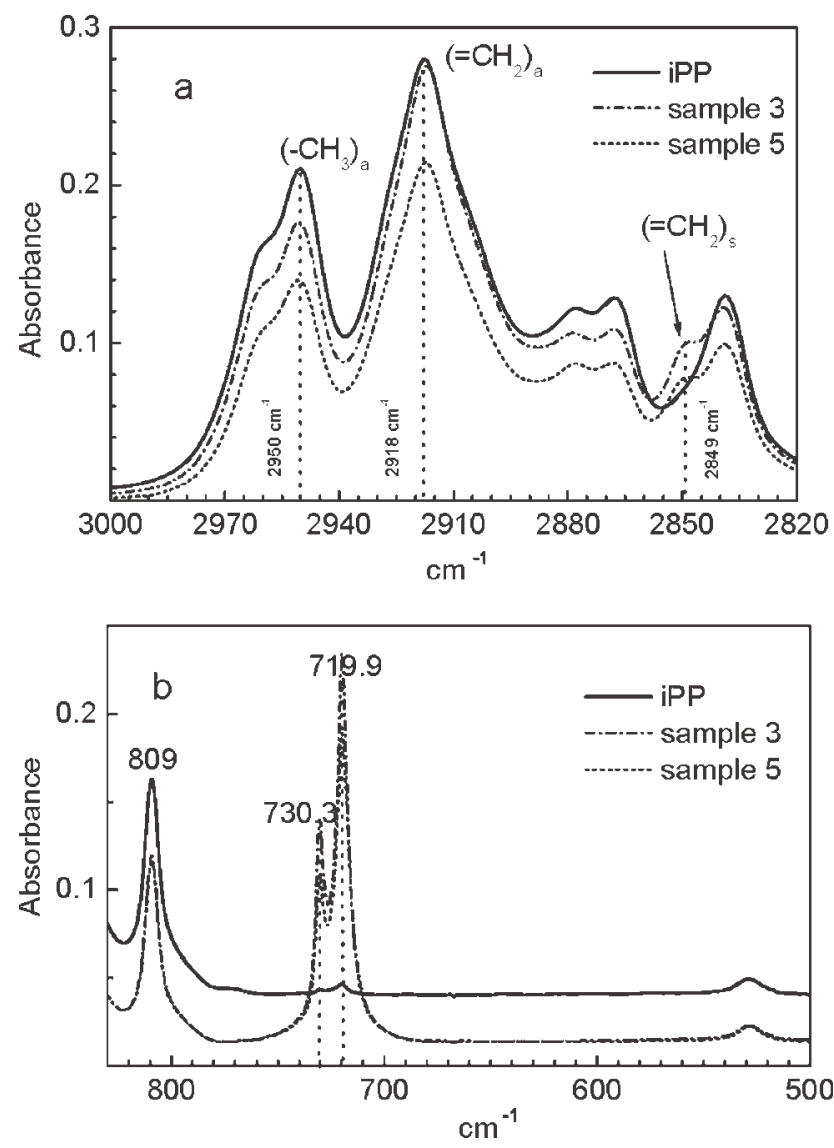

Figure 3 FTIR spectra of the unmodified iPP and samples 3 and 5. (a) Region $2820-3000 \mathrm{~cm}^{-1}$, (b) region 500-830 $\mathrm{cm}^{-1}$. See Table I for sample compositions.

where $\sigma_{e}$ is the surface free energy and $T_{m}^{0}$ is the equilibrium melting point of each component. In addition to the $\Delta H_{m}^{\infty}$ values listed for both components, ${ }^{21}$ in this calculation we have used: for the iPP, $T_{m}^{0}=460.7 \mathrm{~K}^{20}$ and $\sigma_{e}=100 \mathrm{erg} / \mathrm{cm}^{2} ;{ }^{22}$ for the PE, $T_{m}^{0}=414.6 \mathrm{~K}^{20}$ For the surface free energy of PE, we have taken $\sigma_{e}=79 \mathrm{erg} / \mathrm{cm}^{2}{ }^{23}$ However, this $\sigma_{e}$ value is probably an upper limit. In fact, according to our own results, $\sigma_{e}$ in linear PE depends on the molecular weight, its value ranging between 79 and $91 \mathrm{erg} / \mathrm{cm}^{2} .{ }^{23}$ As the melting temperature found in the thermograms of the crosslinked samples for the first maximum is about $125^{\circ} \mathrm{C}$, i.e. relatively low, we think that the PE originated during the crosslinking process has a low molecular weight and/or is not linear, but branched. By using eq. (1), we obtained $l_{c}^{\mathrm{PE}}$ values of $13-14 \mathrm{~nm}$, and $l_{c}^{\mathrm{iPP}}$ values between 22 and $26 \mathrm{~nm}$, very close to the one found for pristine $\mathrm{iPP}$, that is $23 \mathrm{~nm}$.

\section{Fourier transform infrared spectroscopy}

Region $2800-3000 \mathrm{~cm}^{-1}$

Figure 3 shows only the FTIR spectra of the pure iPP and the crosslinked samples 3 and 5 for the sake of clarity. However, all the crosslinked samples behave in the same way. Just to furnish a first, rough estimate of the fraction $F_{\mathrm{iPP}}$ of iPP (both in the amorphous and in the crystalline states) still present in the samples after introducing the crosslinking agents, we consider the heights $h$ of the peaks at 2918 and $2950 \mathrm{~cm}^{-1}$, which are attributed to the $\mathrm{CH}_{2}$ and $\mathrm{CH}_{3}$ antisymmetric stretching modes, respectively. ${ }^{24}$ Table IV reports the ratios $R \equiv h_{\mathrm{CH} 2} /$ $h_{\mathrm{CH} 3}$ for the different samples. Now, let $R_{0}(=1.28$ in the present case) be the value obtained for bare iPP and let $R_{i}$ be the value of Sample $i$. Then $R_{i}>R_{0}$ means that part of the $\mathrm{CH}_{3}$ groups disappeared (i.e. iPP disappeared), and the relative enhancement of the $\mathrm{CH}_{2}$ peak height with respect to the $\mathrm{CH}_{3}$ one is ascribed to a corresponding PE fraction appearing in the system. Thus, $F_{\mathrm{iPP}}=R_{0} / R_{i}$. Of course, for a more exact calculation, $R$ should be estimated from the areas of the peaks, but here we just want to get an approximate evaluation of $F_{\mathrm{iPP}}$, whose values are also listed in Table IV.

In the same region $\left(2800-3000 \mathrm{~cm}^{-1}\right)$, we also find another indication of the appearance of new ethylenic chains. It is the presence, in the crosslinked material, of a band at $2849 \mathrm{~cm}^{-1}$. This band is characteristic of the symmetric stretching mode of the $-\mathrm{CH}_{2}-$ groups $^{24}$ and is not present in the pristine iPP [see Fig. 3(a)].

\section{Region $500-830 \mathrm{~cm}^{-1}$}

In Figure 3(b) we observe, in the crosslinked samples, the doublet at 720 and $730 \mathrm{~cm}^{-1}$, characteristic of the rocking mode of the $\left(-\mathrm{CH}_{2}-\right)_{n}$ sequences in PE when $n=4 .{ }^{25}$ This finding also confirms the creation of new ethylenic chains as a consequence of the crosslinking process.

\section{NMR}

The ${ }^{13} \mathrm{C}$ solid state NMR spectra of pure iPP and some of the crosslinked X-iPP materials, i.e., samples 1, 3, and 5, are shown in Figure 4.

TABLE IV

Ratio $R \equiv h_{\mathrm{CH} 2} / h_{\mathrm{CH} 3}$ (see text for definition); Fraction of Unmodified iPP, $F_{\mathrm{iPP}}$, and Fraction of the Generated Ethylenic Chains, $F_{\mathrm{PE}}$, Present in the Sample After the Crosslinking Process

\begin{tabular}{cccc}
\hline Sample & $R$ & $F_{\text {iPP }}($ FTIR) & $F_{\mathrm{PE}}(\mathrm{NMR})$ \\
\hline iPP & 1.28 & 1 & 0 \\
1 & 1.73 & 0.74 & 0.21 \\
2 & 1.46 & 0.88 & 0.20 \\
3 & 1.59 & 0.81 & 0.22 \\
4 & 1.71 & 0.75 & 0.23 \\
5 & 1.50 & 0.85 & 0.21 \\
6 & 1.53 & 0.84 & 0.21 \\
\hline
\end{tabular}




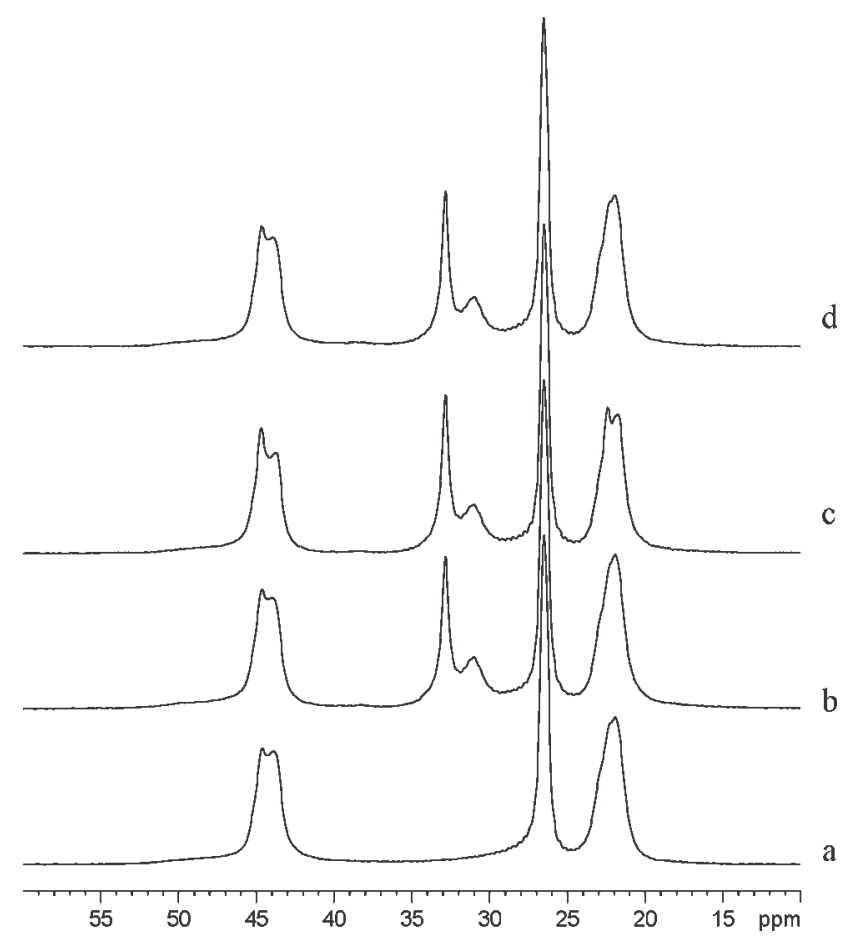

Figure $4{ }^{13} \mathrm{C}$ solid state NMR spectra for: (a) unmodified iPP, (b) sample 1, (c) sample 3, (d) sample 5. Compositions are given in Table I. The assignation of the peaks is as follows: For the iPP: doublet at 44.6 and 43.9 ppm (methylene groups $\left.-\mathrm{CH}_{2}-\right)$, peaks at $26.5 \mathrm{ppm}(-\mathrm{CH}<$ tertiary groups) and $21.9 \mathrm{ppm}$ (methyl groups $\mathrm{CH}_{3}$ ). For the PE: peaks at 31.0 (amorphous $-\mathrm{CH}_{2}-$ sequences) and 32.8 ppm (crystalline $-\mathrm{CH}_{2}-$ sequences).

As it is well known, pure iPP [Fig. 4(a)] exhibits, on its $\alpha$-form, a doublet at 44.6 and $43.9 \mathrm{ppm}$, characteristic of the methylene groups $-\mathrm{CH}_{2}-$, an intense peak at $26.5 \mathrm{ppm}$, from the $-\mathrm{CH}<$ tertiary groups, and finally, the peak originated by the methyl groups $-\mathrm{CH}_{3}$ at $21.9 \mathrm{ppm} \cdot{ }^{26,27}$ In the NMR spectra of the modified samples 1, 3, and 5 [Fig. 4(bd)] the most outstanding characteristic is the appearance of two peaks, at 31.0 and $32.8 \mathrm{ppm}$, which are not present in the pristine iPP. In polyolefins, these peaks are attributed to the presence of sequences $-\mathrm{CH}_{2}-$ in their crystalline (32.8 ppm) and amorphous $(31.0 \mathrm{ppm})$ forms. ${ }^{28}$ The spectra of samples 2 , 4 , and 6, not presented here, also show the new two peaks. From the ratio between the intensity of the PE peaks to the total intensity in each spectrum, the proportion of the generated ethylenic chains can be calculated. This proportion varies between 20 and $23 \%$ of the total material (see Table IV). In addition, the crystallinity of the ethylenic chains, calculated from the ratio of intensities between the peaks at 32.8 and $31.0 \mathrm{ppm}$, is about $51-54 \%$. However, as indicated in the experimental part, the NMR spectra included in this study have been taken by using the $\mathrm{CP}$ method. This method tends to overvalue the crystalline contribution in relation to the amorphous one. ${ }^{29}$ For this reason, we consider the crystallinity values of the PE chains derived from the DSC study to be more realistic. These values, listed in Table III, are in the range $27-30 \%$.

In addition, even if the degree of magnification of the spectra shown in Figure 4 is not enough as to detect them, all samples exhibit little peaks at 38.1, 48.0 , and $49.6 \mathrm{ppm}$. This is an indication of the presence of a small proportion of syndiotactic polypropylene, sPP. ${ }^{29,30}$ However, in the region 48-49 ppm there could be also some overlapping with other resonances due to the $-\mathrm{CH}_{2}-$ groups from the amorphous parts of iPP. ${ }^{29}$ Thus, the maximum amount of sPP can be estimated to be about 3\% in the unmodified sample and even smaller (1.8-2.3\%) in all crosslinked samples.

Moreover, the degree of disorder of the iPP chains can be estimated from the ratio: $\mathrm{A}_{44.0} /$ $\left(\mathrm{A}_{44.0}+\mathrm{A}_{44.7}+\mathrm{A}_{43.6}\right)$, where $\mathrm{A}_{44.0}$ is the area of the peak at $44.0 \mathrm{ppm}$ (characteristic of the $-\mathrm{CH}_{2}-$ groups present in the more disordered $\alpha_{d}$-phases), ${ }^{29}$ and $\mathrm{A}_{44.7}$ and $\mathrm{A}_{43.6}$ are the areas of the peaks at 44.7 and $43.6 \mathrm{ppm}$, originated by the methylene $-\mathrm{CH}_{2}-$ groups in the more ordered $\alpha_{2}$ phase, ${ }^{29}$ respectively. This degree of disorder varies between 0.18 for sample 3 and 0.32 for sample 6, provided that all the crosslinked samples have been subjected to the same thermal treatment.

\section{DISCUSSION}

\section{Mechanical and calorimetric properties}

According to Chodák and Karger-Kocsis, ${ }^{12,13}$ in presence of coagents such as hydroquinone and benzoquinone, the mechanical properties of the modified iPP seem to be less affected by degradation as compared to the other crosslinking initiating systems. For instance, an improvement of the impact resistance at low temperature and a lower brittle-ductile transition temperature, were observed. In our method, we use sulfur as coagent; in fact, our experimental results indicate that, whereas the hardness $\mathrm{H}$ of the samples is not so much influenced by the crosslinking reaction, the impact strength is clearly improved, especially in sample number 5 (see Table II). ${ }^{2}$

DMTA results show that, in the modified samples, the $T_{g}$ value is shifted several degrees above the one obtained for the iPP [Fig. 1(c)]. In addition, in all the crosslinked samples the intensity of this relaxation is notably smaller. These effects can be explained as due to the mobility decrease of the chains originated by the crosslinking process. On the other hand, instead of the wide temperature range (from -130 to $-30^{\circ} \mathrm{C}$ ) in which the $\gamma$-relaxation for the iPP takes 
place, in the modified samples a much narrower one (from -130 to $-80^{\circ} \mathrm{C}$ ) appears, showing a more clear maximum between -100 and $-110^{\circ} \mathrm{C}$ [see Fig. 1(b)]. According to Khonakdar, ${ }^{31}$ this maximum could be related to the $T_{g}$ of the PE.

Concerning the $\alpha^{\prime}$-relaxation, the intensity of this process in most crosslinked samples is lower than in pure iPP.

On the other hand, the above DSC, FTIR, and NMR results confirm that the crosslinking process gives rise to the formation of new ethylenic chains at expenses of the iPP initially present. Thus, from DSC, it is seen that, in the crosslinked samples, a new melting peak appears at about $125^{\circ} \mathrm{C}$ (Fig. 2, and Table III) that can be ascribed to the presence of PE chains. ${ }^{2} \mathrm{Ta}$ ble II collects as well the hardness values $H_{\text {exp }}$ from a preceding publication ${ }^{2}$ for all the studied samples. We can consider that the crosslinked samples are, in fact, blends of iPP plus PE. To explain the mechanical behavior of these blends, we apply the additivity law of a two component system to evaluate the hardness $\mathrm{H}$ of the iPP/PE blends thus obtained:

$$
H=\Phi H^{\mathrm{PE}}+(1-\Phi) H^{\mathrm{iPP}}
$$

where $\Phi$ and (1- $\Phi)$ are respectively the weight fraction of PE and iPP.

In addition, we assume the two phase model for the hardness of a semicrystalline polymer:

$$
H=H_{c} \alpha+H_{a}(1-\alpha)
$$

where $H_{c}$ and $H_{a}$ are the intrinsic hardness values for the crystalline and amorphous phases, respectively, and $\alpha$ is the volume fraction of the crystalline material. By combination of the additivity law (3) and eq. (4), and taking into account that we can approximate $H_{a}^{\mathrm{PE}} \cong 0$, we are led to the expression:

$$
H=H_{c}^{\mathrm{PE}} \alpha^{\mathrm{PE}} \Phi+\left[H_{c}^{\mathrm{iPP}} \alpha^{\mathrm{iPP}}+H_{a}^{\mathrm{iPP}}\left(1-\alpha^{\mathrm{iPP}}\right)\right](1-\Phi)
$$

This expression describes the microhardness of a binary blend in terms of the hardness values of the independent crystalline and amorphous components. By interpolation of the PE data shown in Figure 10 of, ${ }^{32}$ we have estimated the hardness of a PE with a crystallinity degree of about 0.3 (see Table III) to be $22 \mathrm{MPa}$, approximately. Thus, we can derive $H_{c}^{\mathrm{PE}} \cong$ $79 \mathrm{MPa}$. In addition, for iPP we assume a value of $H_{a}^{\mathrm{iPP}}=30 \mathrm{MPa}^{33}$ Thus, from the hardness of the unmodified iPP sample, we obtain $H_{c}^{\mathrm{iPP}}=177 \mathrm{MPa}$. By substituting in eq. (5) $H_{c}^{\mathrm{PE}}, H_{c}^{\mathrm{iPP}}, H_{a}^{\mathrm{iPP}}, \alpha^{\mathrm{PE}}, \alpha^{\mathrm{iPP}}$, and $\Phi$ by their corresponding values, we can calculate the hardness values of the samples $H_{\text {calc }}$ (Table II). One sees that the calculated values $H_{\text {calc }}$ are not very far from the experimental ones $H_{\text {exp }}$, i.e., the crosslinked samples follow the additivity law.

\section{Evidence of generated PE chains from FTIR and NMR}

From FTIR, in the modified materials we find several indications of the presence of new PE chains:

a. The variation of the relative intensities of the bands at 2920 and $2950 \mathrm{~cm}^{-1}$ [Fig. 3(a)] in the $\mathrm{X}$-iPP compared to the pristine iPP. ${ }^{24}$ As it was told above, from this variation it is possible to make a rough estimation of the iPP still present in the samples after the crosslinking process.

b. The appearance, in the spectra of the modified samples, of a new band at $2849 \mathrm{~cm}^{-1}$ [Fig. 3(a)], characteristic of the symmetric stretching mode of the $-\mathrm{CH}_{2}-$ groups. ${ }^{24}$

c. The presence, in the crosslinked samples, of the doublet at 720 and $730 \mathrm{~cm}^{-1}$ [Fig. 3(b)], which is known to be related to the rocking mode of the $\left(-\mathrm{CH}_{2}-\right)_{\mathrm{n}}$ sequences in PE when $n \geq 4 .^{25}$

Finally, the NMR results show that, in the crosslinked iPP, two new peaks appear, at 31.0 and 32.8 ppm [see Figs. 4(b-d)]. These peaks are attributed to the presence of ethylenic chains, respectively amorphous and crystalline, ${ }^{28}$ which were absent in the pristine iPP [see Fig. 4(a)]. In addition, as mentioned before, in Figure 1(a) we observe in sample 4 a hardening process (i.e., $E^{\prime}$ increases) taking place just above $120^{\circ} \mathrm{C}$, that is the $\mathrm{PE}$ melting temperature. This hardening process could probably be ascribed to further iPP crystallization previously hindered by the presence of PE crystals.

The most interesting aspect of this study is the fact that the fraction of unmodified iPP, roughly calculated from the FTIR patterns (third column in Table IV), is complementary to the fraction of newly created ethylenic chains derived from the NMR spectra (fourth column in Table IV).

In summary, there is a good agreement among the results obtained by using different techniques to the samples under study, which confirms the validity of our finding concerning the formation of PE chains as a consequence of the crosslinking process.

\section{Coexistence model}

At this stage, we can ask ourselves where the newly generated PE chains (a 0.20 fraction) could appear. As the crystallinity of the initial iPP is 0.40 , that means that the amorphous phase fraction is 0.60 . In the modified samples, $\alpha^{\mathrm{iPP}}$ is only slightly smaller than in the original material (Table III). According to Chodák and Karger-Kocsis, ${ }^{12,13}$ as the crosslinking process takes place in the molten state, it should 


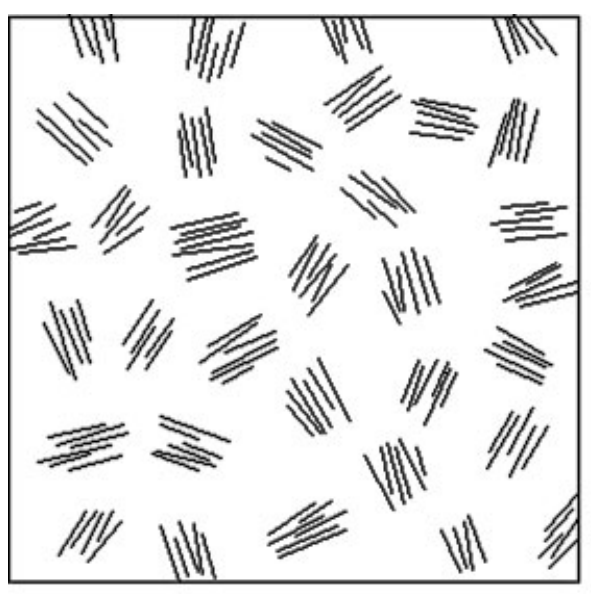

(a)

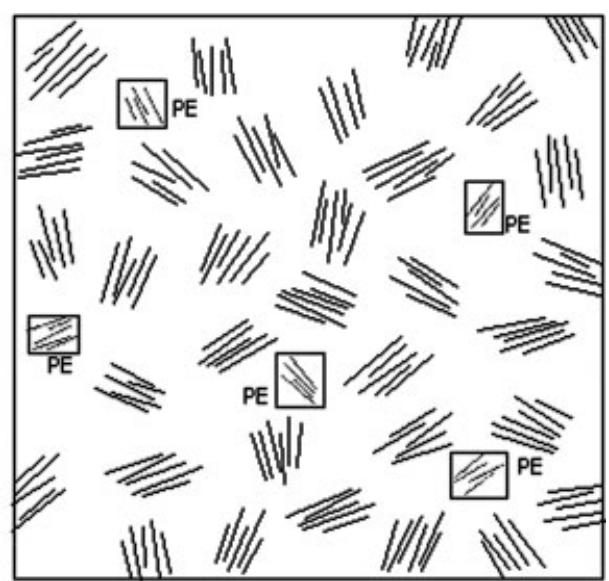

(b)

Figure 5 Schematic drawing of (a) initial pure iPP phase, (b) final modified material, showing the coexistence of both phases iPP and PE. Here, PE stacks of lamellae have been indicated with the letters PE and surrounded by a rectangle, to be distinguished from the larger and more abundant iPP crystals. The tie molecules interconnecting both phases are not shown.

lead to a homogeneous distribution of links. In the presence of sulfur, which acts as a coagent, the scission process and, consequently, the branching are prevented, and the network links are the main structural defects that influence the degree of crystallinity. In fact, the heat of fusion of the iPP-component in the crosslinked material is lower than that of the unmodified iPP. This can be related to the higher defects content and the lower mobility of the chains in the modified polymer. ${ }^{34}$ Similarly to the network links, the PE chains should be homogeneously distributed in the molten material. Thus, one can speculate that, as in, ${ }^{34}$ crosslinks are also formed between iPP and PE macromolecules. In addition, PE is able to crystallize when the temperature is lowered. The degree of crystallinity is, however, quite low, of about 0.30. In Figure 5, we have tried to depict schematically the initial pure iPP phase, consisting of stacks of iPP lamellae distributed at random [Fig. $5(\mathrm{a})]$, and the final modified material, giving rise to the coexistence of both stacks of iPP and PE lamellae [Fig. 5(b)]. The crystalline PE fraction amounts only to about 0.06 . Thus, it is visualized as constituted by few, rather small stacks of crystals.

\section{CONCLUSIONS}

1. The results obtained with the three types of accelerators: tetramethyl tiuram monosulfide (TMTM), tetramethyl tiuram disulfide (TMTD), and 2, $2^{\prime}$ dibenzothiazol disulfide (MBTS), using two different concentrations are quite similar. However, the accelerators differ in their efficiency and kinetic activity.
2. Analysis of data derived from the different techniques used, confirm that the process developed for the reversible crosslinking of iPP gives rise to the generation of ethylenic chains in a proportion of $20-23 \%$.

3. The emerging PE is semicrystalline and its degree of crystallinity is about $27-30 \%$.

4. The crystalline structure of the created PE is not so much affected by the type or concentration of the crosslinking agents.

5. The presence of the amorphous ethylenic fraction originated in the process is shown to contribute to the high impact strength performance shown by the crosslinked samples.

The authors thank Dr. M. Pieruccini, from the "Istituto per i Processi Chimico-Fisici", Sezione di Messina, CNR, Messina, Italy, for his collaboration concerning the DMTA, DSC, and FTIR measurements.

\section{References}

1. Bouhelal, S. U.S. Pat. 6,987,149 (2006).

2. Bouhelal, S.; Cagiao, M. E.; Benachour, D.; Baltá Calleja, F. J. J Appl Polym Sci 2007, 103, 2968.

3. Bouhelal, S.; Cagiao, M. E.; Khellaf, S.; Benachour, D.; Baltá Calleja, F. J. J Appl Polym Sci 2008, 109, 795.

4. Khonakdar, H. A.; Morshedian, J.; Mehrabzadeh, M.; Wagenknecht, U.; Jafari, S. H. Eur Polym J 2003, 39, 1729.

5. Khonakdar, H. A.; Jafari, S. H.; Wagenknecht, U.; Jehnichen, D. Radiat Phys Chem 2006, 75, 78.

6. Mercier, J. P.; Maréchal, E. Chimie des Polymères (Traité des Matériaux); Presses Polytechniques Romandes: Lausanne, 1996; Vol. 13, Chapter 9, p 353.

7. Khonakdar, H. A.; Jafari, S. H.; Taheri, M.; Wagenknecht, U.; Jehnichen, D.; Häussler, L. J Appl Polym Sci 2006, 100, 3264. 
8. Busfield, W. K. Eur Polym J 1981, 17, 333.

9. Fritz, H.-G.; Stöhrer B. Int Polym Proc 1986, 1, 31.

10. Berzin, F.; Vergnes, B.; Delamare L. J Appl Polym Sci 2001, 80, 1243.

11. Berzin, F.; Vergnes, B.; Canevarolo, S. V.; Machado, A. V.; Covas, J. A. J Appl Polym Sci 2006, 99, 2082.

12. Chodák, I. Prog Polym Sci 1995, 20, 1165.

13. Karger-Kocsis, J. Polypropylene. An A-Z Reference; Kluwer Academic Publishers: Dordrecht, 1999; Chapter 18, p 128.

14. Chodák, I.; Lazar, M. J Appl Polym Sci 1986, 32, 5431.

15. Romani, F.; Corrieri, R.; Braga, V.; Ciardelli, F. Polymer 2002, 43,1115

16. Kubo, J.; Otsuhata, K.; Ikeda, S.; Seguchi, T. J Appl Polym Sci 1997, 64, 311.

17. Arranz-Andrés, J.; Peña, B.; Benavente, R.; Pérez, E.; Cerrada, M. L. Eur Polym J 2007, 43, 2357.

18. Prieto, O.; Pereña, J. M.; Benavente, R.; Pérez, E.; Cerrada, M. L. J Polym Sci Part B: Polym Phys 2003, 41, 1878.

19. Jourdan, C.; Cavaille, J. Y.; Pérez, J. J Polym Sci Part B: Polym Phys 1989, 27, 2361.

20. Jarrigeon, M.; Chabert, B.; Chatain, D.; Lacabanne, C.; Nemoz, G. J Macromol Sci Phys 1980, B17, 1.

21. http://athas.prz.rzeszow.pl/
22. Flores, A.; Aurrekoechea, J.; Gensler, R.; Kausch, H. H.; Baltá Calleja, F. J. Colloid Polym Sci 1998, 276, 786.

23. Baltá Calleja, F. J.; Santa Cruz, C.; Bayer, R. K.; Kilian, H. G. Colloid Polym Sci 1990, 268, 440.

24. Bellamy, L. J. The Infrared Spectra of Complex Molecules; Methuen: London/Wiley: New York, 1964; Chapter 2, p 14

25. Bellamy, L. J. The Infrared Spectra of Complex Molecules; Methuen: London/Wiley: New York, 1964; Chapter 2, p 27

26. Bunn, A.; Cudby, M. E. A.; Harris, R. K.; Packer, K. J.; Say, B. J. Polymer 1982, 23, 694.

27. Gómez, M. A.; Tanaka, H.; Tonelli, A. E. Polymer 1987, 28, 2227.

28. Earl, W. L.; VanderHart, D. L. Macromolecules 1979, 12, 762.

29. Comotti, A.; Simonutti, R.; Bracco, S.; Castellani, L.; Sozzani, P. Macromolecules 2001, 34, 4879.

30. Sozzani, P.; Simonutti, R.; Galimberti, M. Macromolecules, 1993, 26, 5782.

31. Khonakdar, H. A.; Jafari, S. H.; Hässler, R. J Appl Polym Sci 2007, 104, 1654.

32. Flores, A.; Ania, F; Baltá Calleja, F. J. Polymer 2009, 50, 729.

33. Martínez Salazar, J.; García Tijero, J. M.; Baltá Calleja, F. J. J Mater Sci 1988, 23, 862.

34. Chodák, I.; Janigová, I.; Romanov, A. Makromol Chem 1991, 192, 2791. 